\title{
Bakım Kavramı Işığında Hemşirelik Bakımı ve Etkileyen Faktörler
}

\author{
Şenay Gülø
}

Hacettepe Üniversitesi, Hemşirelik Fakültesi, Ankara, Türkiye

Dr. Şenay Gül
Illetişim:

Dr. Şenay Gül

Hacettepe Üniversitesi, Hemşirelik Fakültesi Hemşirelik Esasları Anabilim Dalı, Ankara, Türkiye

Tel: +903123051580

E-Posta: senaygundogmus@gmail.com
Gönderilme Tarihi : 15 Haziran 2017

Revizyon Tarihi : : 07 Ağustos 2017

Kabul Tarihi : : 11 Ağustos 2017
ÖZET

İnsanlığın tarihiyle başlayan ve insanın en temel varoluşsal niteliği olan bakım, farklı tanımları olan, ayrıca ilişkisel, fenomenolojik, öznel ve etik yönleri olan çok boyutlu bir olgudur. Bakım yalnızca hemşireliğe özgü olmayan, ancak hemşirelik için özgün olan bir kavramdır. İnsanın doğduğu andan itibaren varlığını sürdürebilmesi için bakıma muhtaç olması, hemşireliğin var olma ve vazgeçilmez olma sebebidir. Hemşirelik için temel dayanak ve özgünlük arz eden ve birçok boyutu olan hemşirelik bakımı; hemşirelerin mesleki ve bireysel özellikleri, sosyal, siyasal, ekonomik, kurumsal pek çok faktörden etkilenmektedir.

Bu makalede bakım kavramının anlamı, filozoflar ve psikologlar tarafından nasıl ele alındığı, hemşirelik teorisyenlerin bakış açısından hemşirelik bakımı ve hemşirelik bakımını etkileyen faktörler ele alınmıştır.

Anahtar sözcükler: Bakım kavramı, hemşirelik bakımı, profesyonellik

\section{NURSING CARE IN THE LIGHT OF CARE CONCEPT AND AFFECTING FACTORS}

\section{ABSTRACT}

Care is a multidimensional phenomenon with different definitions, more important, phenomenological, fundamental and ethical aspects, which are the existential quality of human history and human being. Care is not unique to nursing but it is a unique concept for nursing. The fact that you need to be taken care of so that you can continue to exist from the moment of birth is the reason for nursing to exist and it is indispensable. Nursing care, which has a basic basis and originality for nursing and has many dimensions; is influenced by the professional and individual characteristics of nurses, many social, political, economic and institutional factors. In this article, the meaning of caring concept, how care is evaluated in the fields of philosophy and psychology, factors affecting nursing care and the viewpoints from theorists are discussed.

Keywords: Care concept, nursing care, professionalism

B akım, insanlığın tarihiyle başlayan, çeşitli biçimlerde tanımlanmış olmasına karşın, üzerinde uzlaşılan tek bir tanımı olmayan ancak ilişkisel, fenomenolojik, öznel ve etik yönleri olan çok boyutlu bir olgudur. Bakım yalnızca hemşireliğe özgü olmayan, ancak hemşirelik için özgün bir kavram olmanın yanı sıra çoğunlukla hemşireler tarafından sürdürülen bir uğraştır. İnsanın doğduğu andan itibaren varlığını sürdürebilmesi için bakıma muhtaç olması hemşireliğin var olma ve vazgeçilmez olma sebebidir.

Bakım terimi Türk Dil Kurumu Sözlüğü 'ne göre; "bakma işi, bir şeyin iyi gelişmesi, iyi bir durumda kalması için verilen emek" olarak tanımlanmaktadır (1). Bu kapsamda ele 
alındığında bakım, herhangi bir nesneye ya da bir başkasına değer ve emek vermeyi, ilgi ve özen göstermeyi içerir ve bakım, yöneldiği nesne ya da özneye değer yüklemektedir. Türk Dil Kurumu Sözlügü̈'nde yer alan bir diğer tanıma göre ise bakım "birinin, beslenmesi, giyinmesi vb. gibi gereksinimleri üstlenmek ve bunları sağlamak" olarak belirtilmiştir (1). Bu tanım incelendiğinde bakım, kendi gereksinimlerini karşılayamayan bir kişi için, yani bir başkası için bakma sorumluluğunun üstlenilmesi olarak yorumlanmaktadır.

Ingilizce sözlüklerde de "bakım" kavramının isim, fiil ve sıfat anlamları yer almaktadır. İsim olarak "bakım" (care): ilgi, dikkat, gözetim, özen, önem; sıfat olarak ilgili, özenli, şefkatli, sevecenlilik; fiil olarak ise (to care, to take care) bakım vermek; birine karşı özenli olmak, hazır olmak, istekli olmak, saygılı olmak ve ilgili olmak olarak tanımlanmıştır (2-4).

Biyoetik Terimleri Sözlüğü'nde ise bakım "başka bir kişiyle kurulan ilişkide ortaya çıkan bir duyusal tutum, yaşanan moral bir duygu olan ilginin, tıp uygulaması bağlamında dile getirilmesidir. Hasta bakımı, hekim ve hemşireler başta olmak üzere diğer sağlık çalışanlarının ana uğraşısıdır" şeklinde tanımlanmaktadır (5).

Bakım kavramı, filozof ve psikologlar tarafından farklı şekillerde tanımlanıp yorumlanmıştır. Reich'in bildirdiğine göre Filozof Seneca (M.Ö 4-65) bakımı; insanları üzen, sıkıntı veren bir olgu olarak kabul edilmesinin aksine, insanı Tanrı seviyesine yükselten bir olgu olarak açıklamıştır. Seneca için, hem insanların hem de Tanrının iyiye ulaşmak için akıl güçleri vardır. Tanrı doğası gereği iyidir, fakat insanlar iyiyi "bakım" ile mükemmelleştirmektedir (6).

Søren Kierkegaard (1813-1855), bakım kavramına açıklık getiren Danimarkalı filozof ve ilahiyatçıdır. Kierkegaard'a göre var olmak; çabalayan, seçimde bulunan ve karar veren bir birey olmayı gerektirir. Onun felsefesinde insan öznel ve özgün bir varlıktır (7). Ona göre bakım, insan hayatını anlamak için temel olan şeydir ve insan özgünlüğünün anahtarıdır. Kierkegaard bakımı bireysel, subjektif ve psikolojik bir oluşum olarak görmektedir (6).

Yirminci yüzyılın filozoflarından olan Martin Heidegger'e göre (1889-1976) bakım, felsefi düşünce sisteminin tam merkezinde olan bir kavramdır (6). Heidegger'in "Dasein" diye belirttiği kavram, Almanca 'da gündelik dilde herhangi bir var olanın orada var olduğunu anlatmak için kullanılabilecek bir sözcüktür. Dasein'e varlığını veren ve temel yapısı olan şeyin "ilgi" (cura) olduğunu öne sürmektedir
$(6,8)$. Heidegger bakımla ilgili olarak, varoluş için zorunlu olan öteki insanlar için endişe, kaygı, üzüntü duymak anlamına gelen "sorge" terimini kullanır $(8,9)$. Ona göre bakım varoluş için elzemdir; çünkü bir başkası için ilgi, kaygı olmaksızın hiçbir şey yapılamaz. Heidegger 'dünyada var olmak, özünde ilgili olmaktır' derken (6) aslında bakımın hem doğuştan gelen bir olgu olduğunu hem de duyuşsal bir boyutu olduğunu ifade etmektedir (10).

Heidegger aynı zamanda Besorgen (diğerlerinin ihtiyaçlarını sağlamak anlamında ilgilenmek) ile Fürsorge'ı (özenli bakımı- solicitous care) kıyaslamaktadır. Diğerleri ile zorunlu bir şekilde bağlantılı olan insanın kendisi (Dasein), bakım yoluyla iki şekilde diğerlerinin dünyasına girmektedir. Besorgen olarak nitelenen ilgilenme, diğerinin ihtiyaçlarını karşılamaya yöneliktir ve ilgilenen kişide çok fazla nitelik olmasına gerek yoktur. Fakat ona göre insanlar sadece makineler gibi bu şekilde ilgilenilmesi gereken varlıklar değillerdir; onlar da varoluşları diğerlerine bağlı kişilerdir. Bundan dolayı onlar sadece hizmet objeleri değil özen gösterilmesi gereken varlıklardır (Fürsorge) (6). Heidegger bu iki kavram ile ilgili yapmış olduğu açıklamasıyla bakımı hem fiziksel hem de duyuşsal yönleriyle ele almıştır.

Amerikalı felsefeci ve feminist etikçi Martha Craven Nussbaum (1947), bir yaşamın "iyi" bir yaşam olarak tanımlanabilmesi için bazı niteliklere sahip olması gerektiğini savunur. İnsanlar bebeklik ve çocukluk dönemlerinde yardıma ve bakıma gereksinim duyarlar ve tek başlarına varlıklarını sürdüremezler. İnsan, insan için kaygı duyan, insana ilgi ve şefkat duyan bir varlık omasının yanı sıra insana karşılıklı ilgi ve kaygı bağlarıyla bağlıdır. Nussbaum, insanın temel işlevsel kapasitelerini de listelemiştir. Bunlar arasında insanın sağlıklı olma olanağının sağlanması yer almaktadır. Nussbaum insanı anlama ve tanımanın; merhamet, şefkat, acıma, ilgi ve saygı gibi ahlaki duygularla olabileceğini savunmaktadır. Nussbaum'a göre merhamet, acı ve şefkat insan olmanın temel kavramlarıdır. Ayrıca Nussbaum (2002) bakımın genellikle kadının sorumluluğunda bir olgu olarak değerlendirildiğini ifade etmekle birlikte, bakımı bir adalet sorunu olarak ele almıştır (11).

Levinas'ın felsefesi açısından bakım kavramını incelediğimizde, bakım ilişkisinin asimetrik bir ilişki olduğunun ve bu ilişkide bize ahlaki sorumluluk yükleyen şeyin aslında "ötekinin yüzü" olduğunun ifade edildiğini görmekteyiz. "Ötekinin yüzü", bedeni, duygu ve düşünceleri ile birlikte bir bütün olan insan, bizi ahlaki sorumluluk üstlenmeye davet eden metaforik bir yüzdür. Ahlaki sorumluluk ya da 
etik, ötekinin yüzü ile ilişkiye girdiğimiz anda başlamaktadır. Bu nedenle bakım bir yandan bireylerin yaşamının herhangi bir evresinde ihtiyaç duyduğu evrensel bir gereksinim, diğer yandan da herkese aynı zamanda ahlaki sorumluluk yükleyen bir olgudur (12). Levinas'a göre, 'başkasıyla ilgilenmek, bakımıyla meşgul olmak' ahlaki bir sorumluluktur ve bundan kaçmak mümkün değildir (13).

Hemşireler bakım verebilmek için ahlaki sorumluluklara sahip olmalıdırlar. Paul Ricoeur'a göre etik iyi yaşamdır. Hemşire olarak iyi yaşamanın amacı da acıyı dindirmektir. Ricoeur "Acı çekmek, iyi yaşam hedefinin tam köküne darbe indirmektedir ve acı çekmek hem özsaygıya hem de otonomiye zarar verir. Acı çekenin pasifliğinden dolayı bakım, etik açıdan asimetriktir." diyerek bakım ilişkisinin asimetrik bir ilişki olduğunu vurgulamaktadır. (14).

Varoluşçu psikolog olan Rollo May (1909-1994)'a göre bakım "insan varoluşunun en kurucu fenomenidir". İnsanı, insan yapan şeyin bakım olduğunu ifade eden May, bakımın sevgi ve isteği mümkün kıldığını, aynı zamanda da vicdanlı olmanın kaynağı olduğunu belirtir (6).

Hemşireliğin kuramsal bilgi yüküne önemli katkı sağlayan bazı hemşire teorisyenler de bakım kavramına ilişkin anlayışlarını, hemşirelik bakımı çerçevesinde ifade etmişlerdir. Örneğin; Madeleine Leininger (1978), hemşirelik uygulamalarının temelini oluşturan bir öğreti olarak bakımın değer-inanç sistemini içinde barındıran bir meslek olan hemşireliğin merkezinde yer aldığını ifade etmiştir (15).

Virginia Henderson (1955)'a göre hemşirelik bakımı, hastanın fiziksel, psikolojik, kültürel, entelektüel ve sosyal yönünü göz önünde bulundurarak temel gereksinimlerinin karşılanmasına yardım etmektir (16). Lydia E. Hall (1960) hemşirelik bakımını, bireyin rahatlığını sağlamak, bilgi eksikliğini tanılayıp bireyi bilgilendirmek, bireyin öğrenme gereksinimlerini karşılamak ve bireyin günlük gereksinimlerinin karşılamasına yardım etmek olarak tanımlamıştır $(17,18)$. Dorothea Orem (1971) ise hemşirelik bakımını, sağlıkı/hasta birey biyo-psiko-sosyal gereksinimlerini karşılamada yetersiz kaldığında, yerine getirilmesi gereken bir işlev olarak görmüştür $(19,20)$.

Hemşirelik alanındaki akademik yazın çalışmaları incelendiğinde bakım kavramıyla ilgili üzerinde uzlaşılan ortak bir tanım olmadığı görülmektedir. Yukarıda belirtilen tanımların dışında hemşirelik bakımının duyuşsal ve ahlaki boyutlarını da ele alarak tanımlayan teorisyenler vardır.
Sberill Nones Cronin ve B. Harrison'a (1988) göre bakım, bir süreçtir. Bu süreç içinde hemşire, bireyin kendine özgülüğünü, eşsizliğini görüp dikkate alarak gereksinimlerini yanıtlar ve duygularını farkeder. Zane Robinson Wolf ve arkadaşlarına (1994) göre bakım, etkileşim ve kişilerarası bir süreçtir (21). Anne Boykin ve Savina O. Schoenhofer (1990) bakımı, varlık bilimi (ontoloji), insan bilimi (antropoloji), etik, bilgi bilimi (epistemoloji) ve eğitim bilimi (pedagoji) olarak ele almıştır (22). Carol Green-Hernandez (1991) ve Lennart Fredriksson (1999) bakımı, hasta ve hemşire arasındaki karşılıklı etkileşimin yer aldığı, bir ilişki içinde yaşananları kapsayan bir süreç olarak tanımlamıştır (23). Cortis ve Kendrick (2003) hemşirelik bakımını kapsayıcı ve evrensel bir insani özellik; birilerinin üzerinde etki yaratma, dokunma, şefkat gösterme veya bakım alana empati yapma; karşılıklı düşünce alışverişlerinin yapıldığı kişilerarası bir ilişki; bir terapötik yöntem , ahlaki bir zorunluluk ve aynı zamanda hemşireliğin temel bir erdemi olarak nitelemişlerdir (10).

Hemşirelik bakımını fiziksel, psikomotor beceri, ahlaki ve duyuşsal tüm yönleriyle ele alan tanımlar da mevcuttur. Patricia Larson ve Sandra L. Ferketich'e (1993) göre hemşirelik bakımı, bireylere huzur ve güven duygusu sağlamayı, duygusal ve fiziksel bakım vermeyi amaçlayan eylemler dizisidir (24).

Fry'a göre hastaya bakım vermek, insanın onurunu korumak ve sağlığını yükseltmek yükümlülüğü anlamına gelmektedir. Bu bağlamda hemşirelik bakımı, kaçınılmaz olarak bir tür ahlaki yükümlülüktür. Fry, hemşirelik bakımının hemşirenin benimsemesi gereken merhamet, dürüstlük, vefalılık, yetkinlik gibi ahlaki değerlerin yanı sıra hijyen, organize etme, iş yapma gibi bilimsel bilgiye dayalı bir eylem yönünün de olduğunu dile getirmektedir. Hasta ile hemşire arasındaki ilişki, hastanın bakım gereksinimiyle oluştuğundan özel bir ilişkidir. Bakım bakanla bakılan arasındaki, yani hasta ile hemşire arasındaki ilişkinin temelini oluşturan ahlaki bir kavramdır (25).

Margaret Jean Watson'a (1989) göre bakım, bedensel, zihinsel, ruhsal ve sosyo-kültürel boyutlarda iki kişinin karşılıklı etkileşimi sonucu bilimsel, etik, estetik ve dolayısı ile profesyonel olarak bireyselleşmiş "kişilerarası bir süreç"tir (26).

Görüldüğü üzere bakım yalnızca hemşireliğe özgü değil, ancak hemşirelik için özgün bir kavram ve çoğunlukla hemşireler tarafından sürdürülen bir uğraştır. Hemşirelik için temel dayanak ve özgünlük arz eden ve birçok boyutu olan hemşirelik bakımı; hemşirelerin mesleki ve bireysel özellikleri, sosyal, siyasal, ekonomik, kurumsal pek çok faktörden etkilenmektedir. 
Hemşirelerin mesleki ve bireysel özellikleri, sunulan bakımın niteliğini doğrudan etkilemektedir. Bakımı profesyonel kılan unsurlar; mesleki bilgi, beceri ve tutumları kazanmış meslek üyelerinin lisans eğitimi almış olması, araştırmalar ile oluşturulan mesleki bilgi yükü, toplumun gereksinim duyduğu bir hizmetin sunulması (bakım), meslek üyelerinin uygulamalarında özerk olabilmesi, mesleğe bağlıık, bireysel sorumluluk alma, bakım verenlerin güdülenmesi, mesleki kararlarda hemşirelere rehberlik eden etik kodlarının olması ve mesleki bir örgütün varlığıdır $(27,28)$.

Meslekleşme kriterleri arasında hemşirelerin eğitim düzeyi bakımı etkileyen başıca faktörlerden birisidir. Eğitim düzeyi profesyonelliğin anahtar kriterlerinden biridir ve bilgi ile beceriyi beraberinde getirdiği için bakımı etkilemektedir. Ülkemizde, hemşirelik eğitimi 1955 yılından bu yana lisans düzeyinde verilmektedir. Ancak, Ekonomik Kalkınma ve İşbirliği Örgütü'nün (Organization for Economic CoOperation and Development-OECD) ülkeleri ile karşılaştırıldığında ülkemizde hemşire sayısının yetersiz olması gerekçe gösterilerek esasında 1996 yılında öğrenci alımı durdurulmuş olan Sağlık Meslek Liselerinin devam edilmesine yönelik yasal düzenlemeler yapılmıştır. Bu düzenlemeler arasında 2007 yılında yeniden düzenlenerek yürürlüğe giren Hemşirelik Kanunu'nun Geçici 2. Maddesi, 17.07.2012 tarih ve 28351 sayılı Kanun hükmünde kararname ve son olarak 18 Ocak 2014 tarihinde yürürlüğe giren Hemşire Yardımcılığını ön gören 28886 sayılı kararname sayılabilir (29). Zaten lisans düzeyine temelli olan hemşirelik eğitiminin düzeyinin düşürülmesi ve hemşireler tarafından sunulan bazı bakım işlevlerinin eğitim düzeyi daha düşük birey ve gruplara devredilmesinin bakım kalitesini düşüreceği açıktır. Eğitim düzeyi açısından böylesi farklılıkların mesleki bilgi yükünün oluşturulması ve bilginin uygulama alanına aktarılarak bakımın geliştirilmesine yönelik katkısı da oldukça sınırlanmaktadır $(30,31)$.

Hemşirelerin mesleğe bağlılığı ve motivasyonu bakımı etkilemektedir. Hemşirelik hizmetlerinin insanı konu almasından dolayı dikkatli ve sürekli çalışmayı gerektirmektedir. Nitelikli bir bakım sunabilmeleri için, iş doyumlarının yüksek olması son derece önemlidir (32). Mesleğin toplumsal statüsünün düşük olması, daha çok kadınlar tarafından tercih edilmesi, hemşirelik mesleğinin genellikle istemeden seçilmesi, hemşirelik mesleğinin gelişimini ve dolayısıyla da bakımı olumsuz etkilemektedir.

Hemşirelerin mesleki sorumluluk almaları, meslek üyesi olmalarının bir şartıdır. Mesleki sorumluluk alma da temelde bireylerin bakım sorumluluğunu almalarıdır. Hemşirelerin bireysel sorumlulukları meslek üyelerine, kendine, bakım verdiği bireylere ve çalıştığı kurumlara bir hesap vermeyi gerektirir. Hemşirelik bakımında da sorumluluk; bakımı standartlarına uygun yapmayı, bilgi birikimini, mesleği benimsemeyi ve mesleki özerkliği gerektirmektedir (33). Ancak yukarıda söz edilen meslekleşme kriterleri açısından ülkemizdeki hemşireliğin durumu, uygulamalarda özerkliği ve mesleki sorumluluğu da olumsuz yönde etkilemektedir.

Toplumsal ve sosyal değişmeler, insan hakları ve hasta hakları gibi kavramların ortaya çıkmasını sağlamış ve bu da toplumun hemşireden beklentilerinde önemli bir farkIılaşmaya neden olmuştur. Bu farklılaşmalar içinde hemşirelerin en önemli rolü de hizmet verdikleri hasta veya sağlıklı bireyin haklarını savunma rolü olmuştur. Hemşirelerin hasta savunuculuğu hasta güvenliğinin sağlanması açısından kritik öneme sahip, hemşirelerin bakım, danışmanlık, eğitim gibi diğer rollerini de destekleyen ve geliştirilmesine katkı sağlayan bir roldür (34). Bununla birlikte hemşirelerin hasta savunuculuğu rolü bir sağlık bakım sisteminde kimi zaman hekimlere, diğer sağlık profesyonellerine, meslektaşlarına ve kuruma karşı da olabilmekte ve sağlık ekibi içinde ilişkilerde çatışma yaşanmasına da yol açabilmektedir. Dolayısıyla genişleyen ve gelişen hemşirelik rolleri hasta bakımına katkılarının yanı sıra bazı kaçınılmaz sorunları da beraberinde getirmekte ve bakım kalitesini etkileyebilmektedir.

Hemşirelik bakımını hastaların dini ve kültürel uygulamaları ile sosyoekonomik durumu etkilemektedir. Kültürel ve dini inançlar bireyin sağlık bakım sistemine yaklaşımını, kişisel sağlık uygulamalarını ve hemşire-hasta iletişimini etkilemektedir. Hemşire, bakım vermekle yükümlü olduğu bireyin kültürel ve dini inançlarını bilmediği takdirde bireyin davranışlarını ve inançlarını anlamakta güçlük çekmekte ve etkili bir bakım sunması mümkün olmamaktadır (35). Hemşireler, bakım verdikleri hastaların dini ve kültürel inanç ve uygulamaları bilerek bakımlarını ona göre planlayabilmelidirler.

Bireylerin ekonomik durumu sağlık bakım sisteminden yararlanmayı etkileyen önemli faktörlerden biridir. Sağlık hizmetlerinin maliyetinin giderek yükselmesi ve bireysel ödemelerin artması bireylerin bakım hizmetlerinden yararlanmalarını engellemektedir (36). Bu durumda bakım ihtiyacı olan herkese değil, parası olana sunulmakta, bakımın duyuşsal ve insani boyutu göz ardı edilmekte ve hemşire-hasta iletişimini olumsuz yönde etkilemektedir. 
Hemşirelik bakımını etkileyen bir diğer faktör toplumsal cinsiyet bakış açısıdır. Toplumsal cinsiyet anlayışının etkisiyle toplum içinde kadına yüklenen sorumluluklar ve beklentiler, hastanelerde de hemşirelere yüklenmiştir. Kadının toplumdaki yeri yüzyıllardır hemşireliğin yerini de paralel olarak etkilemiştir. Kadına özgü bir uğraş olarak, değersiz görülen ve toplumsal statüsü düşük olarak algılanan bakımın ağır, stresli ve yorucu çalışma ortamlarında, genellikle yetersiz personel ve araç gereçlerle birlikte sunulmaya çalışılması, bunun karşılığında yetersiz ücret ve saygınlığın artmaması, emeğin görünmezliği hemşirelerde hayal kırıklığı ve tükenmişliğe yol açmaktadır. Sürekli yorgunluk, umutsuzluk, çaresizlik duyguları ile yaşanan duygusal ve fiziksel tükenme, kişisel başarı eksikliğini de beraberinde getirmekte (37) ve hemşire-hasta iletişimini ve bakımı olumsuz yönde etkilemektedir.

Bakımı etkileyen faktörler arasında ülkede uygulanan sağıık politikaları önemli bir yer tutmaktadır. Ülkelerdeki siyasi kararlar, eğitim ve sağlık sistemi gibi önemli alanları doğrudan etkilemektedir. OECD 2013 yılı verilerine göre sağlık profesyonelleri arasında sayı olarak hemşireler ilk sırada yer almaktadır. Sağlık ve eğitim sistemleriyle ilgili alınan bütün siyasi kararlar sağlık personeli içerisinde sayıca fazla olan hemşireleri ve bakım verdikleri hastalarını doğrudan etkilemektedir. Ancak hemşireler bu kararların sadece sonuçlarından etkilenmekte, politikaların belirlenmesinde rol alamamaktadırlar (38). Özellikle ülkemizde yürütülen sağlıkla ilgili politikalar, hemşirelerin mesleki eğitimlerini, unvan ve çalışma yaşamlarını doğrudan etkilemiştir. Hemşirelik mesleğinin eğitim ve öğretiminin nitelik ve niceliği hemşirelik bakımında son derece önemlidir. Daha önce de belirtildiği üzere, ülkemizde hemşire meslek unvanı, bugüne kadar izlenen sağlık politikalarıyla birlikte, özellikle de hemşire sayısındaki yetersizlik neden gösterilerek ortaokul, meslek lisesi, iki yıllık meslek yüksekokulu, dört yıllık meslek yüksekokulu ve çeşitli kurslardan mezun kişilere verilmiştir. Farklı mezuniyet koşullarını gerçekleştirerek mezun olan hemşireler aynı işi yaptıkları halde ayrı ücret almakta ve aynı kalitede bakım sunmaları beklenmektedir $(17,32,39)$

Günümüzde mesleğe yönelik diğer bir sorun hemşirelerin sözleşmeli, kadrolu, taşeron işçi gibi çeşitli pozisyonlarda çalışmaları olarak görülmektedir. Bu pozisyonlar hemşireler arasındaki eşitsizliği giderek arttırmakta, iş güvencesini azaltmakta, çalışma koşullarındaki sürekli değişime uyumu zorlaştırmakta, özel ve devlet kurumuna göre çalışma sürelerindeki değişim hemşirelik bakımını da olumsuz yönde etkilemektedir $(32,39)$.
Ülkemizde hemşireliği ve bakımı etkileyen diğer politik kararları incelediğimizde resmi gazetede 2 Kasım 2011 yılında yayınlanan 663 sayılı "Sağlık Bakanlığı ve Bağlı Kuruluşlarının Teşkilat ve Görevleri Hakkında Kanun Hükmünde Kararname'de "hemşire" kelimesinin hiç geçmediği ve hemşireliğe yer verilmediği görülmektedir. Hemşirelik hizmetleri yönetimi de mesleği hemşirelik olmak zorunda olmayan bakım hizmetleri müdürünün sorumluluğuna verilmektedir. Bu durumda zaten bir çok faktöre bağlı olarak kısıtlı olan mesleki özerkliği ve hemşirelerin kendi uygulamalarıyla ilgili öz denetimini kısıtlamaktadır. Yine 31 Ekim 2012 yılında 3131 sayılı Türkiye Kamu Hastaneleri Kurumu Taşra Teşkilatı Çalışma Usul ve Esasları Hakkında Yönerge'nin yürürlüğe girmesiyle bakım hizmetleri müdürünün görev, yetki ve sorumlulukları ortaya konulmuştur (29). Bu görev, yetki ve sorumluluklar incelendiğinde bakım hizmetlerinden temizlik ve otelcilik hizmetlerine kadar pek çok hizmetten söz edildiği görülmektedir (39). Bu kadar farklı görev ve sorumluluğun bakım hizmetleriyle birlikte yürütülmeye çalışılmasının yanı sıra bu göreve getirilen kişilerin, hemşirelik dışında farklı mesleklerden kişilerin olması hemşirelik mesleğini ve bakımı olumsuz yönde etkileyeceği düşünülmektedir.

Bakımın niteliğini etkileyen diğer faktör; sağlık kuruluşlarındaki sağlık ve yönetim sisteminin biçimi ve örgütsel yapısıdır. Sağlık bakım hizmetleri karmaşık bir yapıya sahiptir. Bu yapı içerisinde farklı meslek üyelerinden hizmet alınması, diğer taraftan hizmetin farklıığı nedeniyle bu hizmetin verildiği hastanelerde de farklılaşmaların olması bakımın niteliğini etkilemektedir.

Sağlık kurumlarında ev idaresi ve kırtasiye işlerinin önemli bir bölümü hemşirelere yüklenmekte, bu kurumlarda hemşireler hasta bakımının yanı sıra kliniği düzenleme, gerekli onarımlar için teknik servis ile iletişimi sağlama, sekretarya işlerini yapma, mekânın temizliğini denetleme ve malzemeleri sağlayıp yazışmaları yapma gibi kendi görev tanımında yer almayan işleri de yapmaktadır (40). Bu durum hemşirelerin hastalarına ayıracakları zamanı sınırlandırarak nitelikli bakım sunmalarının önüne geçmektedir.

Diğer yandan yataklı tedavi kurumlarında; araç-gereç ve nitelikli personel eksikliği, bakım hizmetlerinin bir bölümünün eğitimli hemşireler yerine daha ucuz iş gücünü oluşturan hastabakıcı ve diğer yardımcı personele devredilmesine neden olmaktadır. Bu durum ise bakımın kalitesini azaltırken hasta güvenliğine yönelik riskleri artırmaktadır $(36,41,42)$. 
Sonuç olarak; hemşirelik bakımını etkileyen yukarıda belirtilen faktörlerin ayrıntılı incelenmesi sonucunda açıkça görülmektedir ki sıralanan bu faktörlerin hiçbiri birbirinden bağımsız değildir. Herhangi birinde meydana gelen değişim, bir diğerini ve dolayısıyla bakımı olumlu ya da olumsuz yönde etkilemektedir. İnsanlığın varoluşundan bu yana var olan ve tarih boyunca genellikle kadınlar tarafından üstlenilen bakım; siyasal, sosyal, kurumsal ve mesleki pek çok faktörden etkilenmekte olup bakım verenleri ve bakım alanları da doğrudan etkilemektedir.

\section{Kaynaklar}

1. Akalın ŞH, Toparlı R, Argunşah M, Demir N, Gözaydın N, Özyetgin M. ve ark. Türkçe Sözlük, 11.bs. Ankara: Türk Dil Kurumu Yayınları, 2011.

2. Care. Longman Dictionary of Contemporary English. İngiltere: Pearson Education, 2010.

3. Roget PM. Roget's Thesaurus of English Words and Phrases, Editora Griffo, 2015.

4. Caring. Chambers' Paperback Thesaurus. İngiltere: Editors of Chambers, 2012.

5. Oğuz Y, Tepe H, Örnek- Büken N, Kucur DK. Biyoetik Terimleri Sözlüğü 1.bs. Ankara: Türkiye Felsefe Kurumu, 2005.

6. Reich W. History of the Notion of Care Encyclopedia of Bioethics 5th Volumes. New York: Simon \& Schuster Macmillan, 2014. p. 319-31

7. Cevizci A. Felsefe Tarihi 5. bs. İstanbul: Say Yayınları, 2014

8. Çüçen AK. Martin Heidegger: Varlık ve Zaman 5. bs. İstanbul: Sentez Yayınları, 2012.

9. Escudero JA. Heidegger: Being and Time and the Care for the Self. Journal of Philosophy 2013;3:302-7. [CrossRef]

10. Cortis JD, Kendrick K. Nursing ethics, caring and culture. Nursing Ethics 2003;10:77-88. [CrossRef]

11. Beyaz-Erkızan HN. Aristoteles'ten Nussbaum'a İnsan. Bursa: Sentez Yayıncilık, 2012.

12. Lavoie $M$, De Koninck $T$, Blondeau $D$. The nature of care in light of Emmanuel Levinas. Nursing Philisophy, 2006;7:225-34. [CrossRef]

13. Gözal Ö. Levinas. Fikir Mimarları Dizisi-29. İstanbul: Say Yayınları, 2012.

14. Fredriksson L, Eriksson K. The Ethics of the Caring Conversation. Nursing Ethics 2003; 10:138-48. [CrossRef]

15. McFarland, M. Madeleine Leininger: Culture Care Theoryof Diversity and Universality. In Nursing Theorists and Their Work. Tomey AM, Alligood MR Eds. 6th ed. United States of America: Mosby Inc, 2006.

16. Tomey AM. Virginia Henderson: Definition of Nursing. In Nursing Theorists and Their Work. Tomey AM, Alligood MR Eds. 6th ed. United States of America: Mosby Inc, 2006.

17. Akın Korhan E. Lydia Hall: Öz, Tedavi ve Bakım Teorisi. İçinde hemşirelik Teorileri ve Modelleri. Karadağ A, Çalışkan N, Göçmen Baykara Z Eds. 1. Basım. İstanbul: Akademi Basın, 2017.

18. Fakouri C. Lydia E. Hall: Core, Care and Cure Model. In Nursing Theorists and Their Work. Tomey AM, Alligood MR Eds. 6th ed. United States of America: Mosby Inc, 2006.

19. Taylor S. Dorothea E. Orem: Self- Care Deficit Theory of Nursing. In Nursing Theorists and Their Work. Tomey AM, Alligood MR Eds. 6th ed. United States of America: Mosby Inc, 2006.

20. Şahin AO. Hemşirelik Bakımının Değerlendirilmesi ile İlgili Bir Çalışma. T.C. Marmara Üniversitesi Sağlık Bilimleri Enstitüsü, Hemşirelik Esasları Anabilim Dalı Başkanlığı. Doktora Tezi, İstanbul, 2006.

21. Beck CT. Quantitative Measurement of Caring. Journal of Advanced Nursing 1999; 30:24-32.
22. Boykin A, Schoenhofer SO. Nursing as caring: a model of transforming practice. Boston: Jones and Bartlett, 2001.

23. Covington H. Caring presence: Delineation of a concept for holistic nursing. J Holistic Nurs 2003;21:301-17. [CrossRef]

24. Larson PJ, Ferketich SL., Patients' satisfaction with nurses' caring during hospitalization. West J Nurs Res1993;15:690-707. [CrossRef]

25. Fry ST. Hemşirelik uygulamalarında etik (B.Bağ Çev.). İstanbul: Aktif Yayınevi, 2000.

26. Neil RM \& Tomey MA. Jean Watson: Philosophy and Science of Caring. In Nursing Theorists and Their Work. Tomey AM, Alligood MR Eds. 6th ed. United States of America: Mosby Inc, 2006.

27. Korkmaz F. Meslekleşme ve Ülkemizde Hemşirelik. Sağlık Bilimleri Fakültesi Hemşirelik Derg 2011;59-67.

28. Salvage J. Etkinliğe Doğru Eylem 2. bs. Ankara: Aydoğdu Ofset, 1993.

29. http://www.resmigazete.gov.tr/eskiler/2014/01/20140118-1.htm (Erişim Tarihi: 15.04.2019)

30. Karadağ A. Meslek olarak hemşirelik. Atatürk Üniversitesi Hemşirelik Yüksekokulu Derg 2002;5:55-62

31. Karagözoğlu Ş. Bilim ve bilimsel bir disiplin olarak hemşirelik. II. Ulusal Hemşirelikte Araştırma Sempozyumu, Sempozyum Kitabı, Ankara, 2004.

32. Dinç L. Hemşirelik hizmetlerinde etik yükümlülükler. Hacettepe Tıp Derg 2009; 40:113-9.

33. Köşgeroğlu N. Hemşirelikte Hak ve Sorumlulukların Yerine Getirilmesini Etkileyen Faktörler. Türk Hemşireler Derneği 1995:45:40-1.

34. Pottery PA \& Perry AG. Nursing today. In Fundamentals of Nursing. 6th ed. USA: Elsevier Mosby, 2005.

35. Mete S (2014). Hemşireliğin Temel Kavramları. In Hemşirelik Esasları: Hemşirelik Bilim ve Sanatı. Atabek-Aştı, T, Karadağ A Eds. 1.bs. İstanbul: Akademi Basın ve Yayıncılık, 2014.

36. Dinç L. Bakım kavramı ve ahlaki boyutu. Sağlık Bilimleri Fakültesi Hemşirelik Derg 2010; 74-82.

37. Taycan O, Kutlu L, Çimen S, Aydın N. Bir üniversite hastanesinde çalışan hemşirelerde depresyon ve tükenmişlik düzeyinin sosyodemografik özelliklerle ilişkisi. Anatolian J Psychiatry 2006;7:100-8.

38. http://stats.oecd.org/index.aspx?DataSetCode=HEALTH_STAT (Erişim Tarihi: 26.03.2019).

39. Harmanci AK. Sağlık Sistemi, Sağlık Politikaları ve Hemşirelik Mevzuatı. In Hemşirelik Hizmetleri Yönetimi. Tatar Baykal Ü, Ercan Türkmen E Eds. İstanbul: Akademi Yayıncılık, 2014.

40. Coşkun A. "Perinatal hemşirelik yaklaşımında ekip çalışmasının önemi". Perinatoloji Derg 1996; 4:181-4.

41. Schluter J, Winch S, Holzhauser K, Henderson A. Nurses' moral sensitivity and hospital ethical climate: a literature review. Nursing Ethics 2008; 15:304-21. [CrossRef]

42. Callaghan M. Nursing morale: what is it like and why? Journal of Advanced Nurs 2003:42:82-9. 